\title{
A Study of Prevalence and Risk Factors of Senile Cataract in Tea Garden Community in Dibrugarh District, Assam, India
}

\author{
Dr. Sheshadra Krishna Sonowal ${ }^{1}$, Dr. Jawahar Jyoti Kuli ${ }^{2}$, Dr. Gourangie Gogoi ${ }^{3}$ \\ ${ }_{1}^{1} 3^{\text {rd }}$ year PG Student, Department Of Ophthalmology, Assam Medical College and Hospital, Dibrugarh, Barbari-786002, Assam, India \\ ${ }^{2}$ Prof and HOD, Department Of Ophthalmology,Department of Ophthalmology, Assam Medical College And Hospital, Dibrugarh,Barbari- \\ 786002, Assam, India \\ ${ }^{3}$ Associate Professor, Department Of Community Medicine Assam Medical College and Hospital, Dibrugarh,Barbari-786002,Assam,India
}

\begin{abstract}
Purpose: To find out prevalence of senile cataract in tea garden community and its associationwith risk factors. Methods: A cross sectional study, community based study was undertaken among adults aged 40 years and above in 10 randomly selected tea gardens of Dibrugarh district.Those eligible were subjected to interview and ocular examination using Distant Direct Ophthalmoscopy. The lensopacity was graded and classified after dilation using LOCS III system at the slit lamp for cataract. Result: Out of 1200 eligible persons examined 384 persons were found to have cataract. Data analysis revealed prevalence of $32 \%$. On univariate analysis age, educational status, occupation, socioeconomic status, BMI, family history, history of sunlight exposure, smoking, alcohol consumption and severe diarrhea were found to be significantly associated with senile cataract and on multivariate analysis age, educational status, occupation, family history, smoking and alcohol consumption were found to be significantly associated with senile cataract. Conclusion: Senile cataract appears to have a multi factorial etiology. Though the study provided some clues to the etiology of senile cataract in tea garden community, further studies are needed to know the specific role of these factors in the causation of cataract, so that any preventive or control measures could be initiated in the community.
\end{abstract}

Keywords: Senile cataract, prevalence, tea garden community, risk factors

\section{Introduction}

Cataract is a major cause of avoidable blindness and visual impairment throughout the world. Its incidence is increasing due to increase in life expectancy of the population globally and especially in developing countries. Thereby increasing burden to health care system. According to 2010 World Health Organization (WHO) data, there are 39 million persons who are blind worldwide, with the three leading causes of blindness being cataract (51\%), glaucoma (8\%), and age-related macular degeneration (5\%). ${ }^{1}$ Globally, cataracts cause moderate to severe disability in 53.8 million (2004), 52.2 million of whom are in low and middle income countries. $^{2}$

The WHO / NPCB (National Programme for Control of Blindness) survey has shown that there is a backlog of over 22 million blind eyes (12 million blind people) in India, and $80.1 \%$ of these are blind due to cataract.5 From a public heath perspective, it is desirable to identify risk factors for the development and progression of cataract because although surgical intervention is an effective modality for restoring vision, there remain significant challenges in both delivery and utilization of cataract surgical services. ${ }^{3}$

India is the largest producer and consumer of tea in the world. ${ }^{4}$ Assam is the largest tea producing state in India and contributes about 60 per cent of the total production of India 8. Tea garden population constitutes approximately $1 / 5$ th of state's population. Dibrugarh is the hub of tea industry and situated in the eastern corner of the state. Their working condition, poor socio-economic conditions, ignorance due to illiteracy, over-crowded, addiction to local homemade beer and unhygienic living conditions in the residential colonies make tea garden population vulnerable to various diseases and malnutrition. There may be some also specific health problems, which may be related to their occupation Identification of major risk factors of senile cataract in the tea garden population will be crucial in planning strategies to reduce or delay the development of this condition.The findings allow us to discuss their health scenario against the backdrop of their socio-economic condition and lifestyles, which will have important public health implication.

\section{Aims and Objectives}

- To evaluate the prevalence of senile cataract in tea garden community inDibrugarh district.

- To find out association of different risk factors with the prevalence of cataract.

\section{Methodology}

Ethical clearance was obtained from the institutional ethics committee of Assam Medical College and Hospital, prior to the commencement of the present study.

Selection of Patients 
International Journal of Science and Research (IJSR)

ISSN (Online): 2319-7064

Index Copernicus Value (2013): 6.14 | Impact Factor (2014): 5.611

\begin{tabular}{|l|l|}
\hline Inclusion Criteria: & Exclusion Criteria: \\
\hline - Age more than 40 years. & - History suggestive of congenital, traumatic, or complicated cataract. \\
- Any significant opacity in the lens or its capsule & $\begin{array}{l}\text { - Features not suggestive of senile cataract on slit lamp examination. } \\
\text { suggestive of senile cataract. }\end{array}$ \\
- Patients with hypertension and diabetes are not included in my study \\
psudophakia
\end{tabular}

A community based Cross-sectional Study was conducted among peoples of 40 years of age and above, resides in tea garden of Dibrugarh district for aperiod of one Year (June 2014 to May 2015).The sample size is calculated by using the formula:

$$
=\frac{Z^{2} p q}{d^{2}}
$$

Where $\mathrm{n}=$ Sample Size

$\mathrm{Z}=1.96$ for $95 \%$ confidence interval

$\mathrm{p}=$ Prevalence of cataract among elderly

population in tea garden

$\mathrm{q}=(1-\mathrm{p})$

$\mathrm{d}=$ Allowable error (relative error)

Considering the prevalence of cataract among adult population aged 40 years and above to be $24.86 \%{ }^{5}$ and the relative error to be $10 \%$ the sample size is calculated to be 1161 which is rounded off to 1200.A list of all the tea garden under the Dibrugarh district was prepared and 10 tea gardens were selected from the list by simple random sampling. The sample size of 1200 was equally allocated in those selected tea gardens, i.e.120 cases in each garden. Then in each of these selected tea garden the list of the individuals aged 40 years and above was prepared and from the list the required number of individuals i.e.120 from each garden were selected randomly for the study. Data were collected in a pre-designed pre tested schedule after obtaining permission from the tea garden authority to conduct my study. Written informed consent was taken from each of the participants.

The eligiblepersons were interviewed regarding various

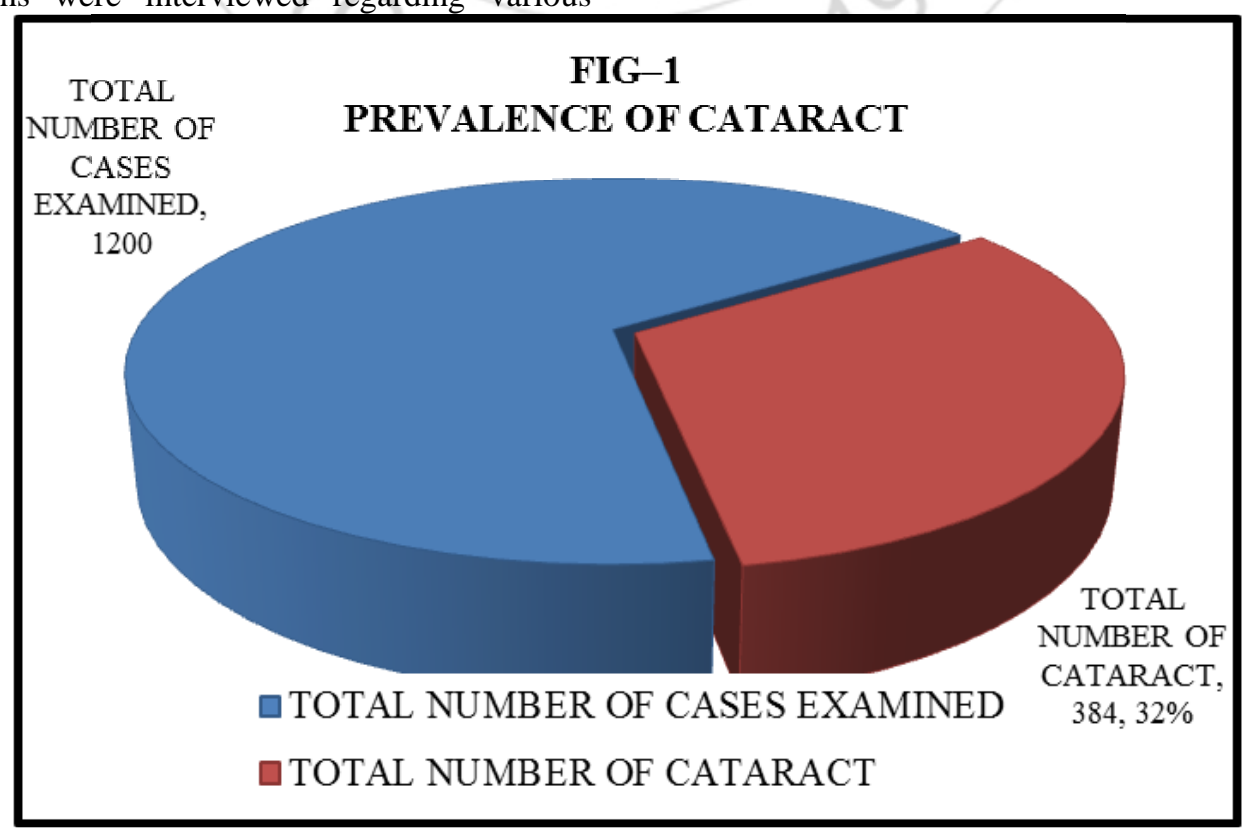

In our study, among 1200 total cases examined, 384 cases were found to have cataract i.e. 32\%. riskfactors namely age, sex, literacy status, socioeconomicstatus, family history, sun light exposure, smoking history, alcohol intake, history of severe diarrhea andintake multivitamin supplements using a pre-designed and pre-testedquestionnaire. This was followed by General PhysicalExamination and ocular examination using torch. Vision was tested in each eye separately with Snellen's chart in Assamese, Hindi, English or C chart. Patient had vision $\leq 6 / 36$,were made fully dilated pupil by instilling tropicamide.8\% and phenylephrine 5\% eye drop into eyes then Distant Direct Ophthalmoscopy was done. Three slitlamp images were taken and compared with standard color photographic plates of cortical cataract, nuclear opalescence, nuclear color and posterior sub capsular cataract and graded according to LOCS III classification. Those cases which were detected early and got operated were examined whether they were pseudophakic or aphakic either in both or single eye were included in my study. Anthropometric measurements height, weight were measured and BMI were calculated.

Statistical analysis was done using mean and percentage. Data are presented as tables, bar diagrams and pie diagrams wherever applicable.Univariate analysis was first done to test associations wherever necessary. Multiple logistic regression (MLR) was used for all the variables which were found significant during univariate analysis. The data was analysed using SPSS 16.0 software.

\section{Results}

Prevalence of Cataract 
Factors Associated With Cataract:

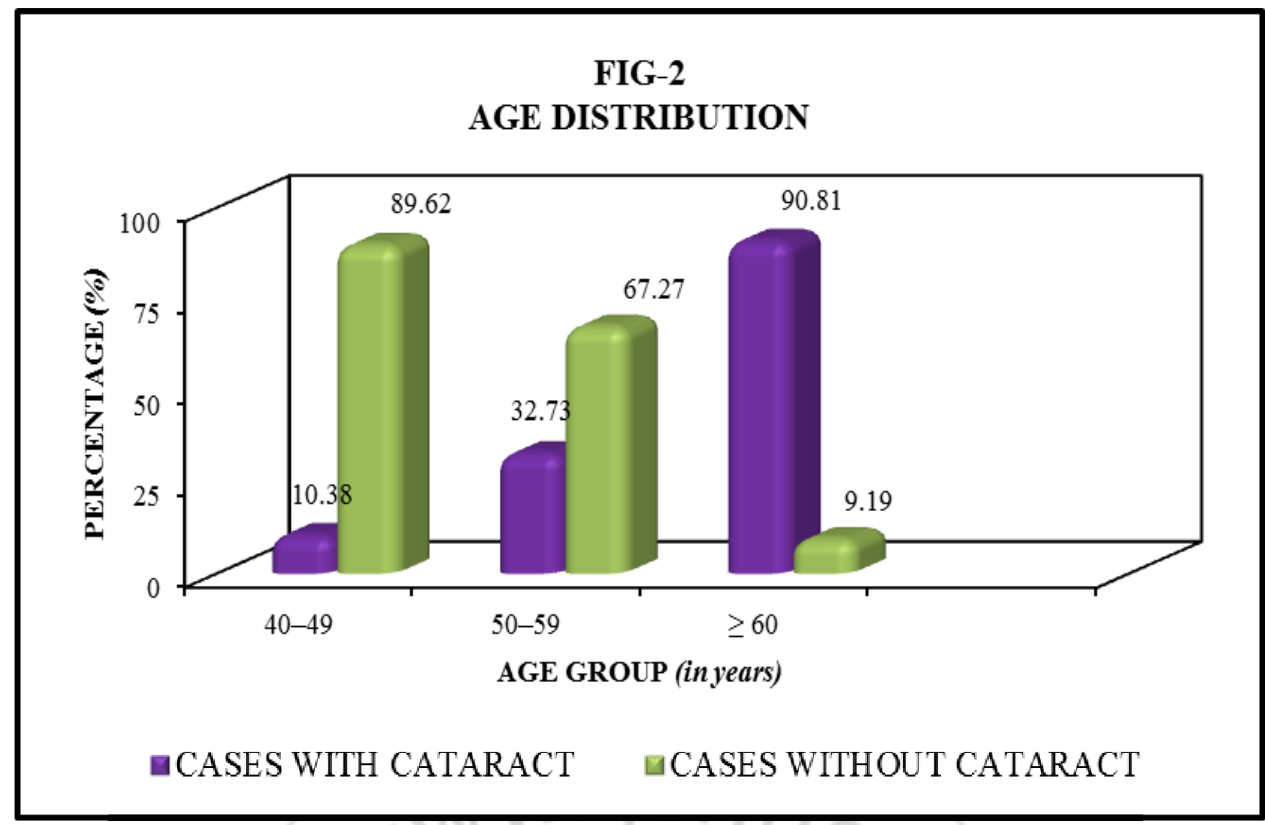

In our study prevalence of senile cataract increases with increasing age, maximum at age $\geq 60$ years (90.81\%),followed by 31.46\%at 50-59 year range and lowest at $40-49 y e a$ range $(10.38 \%)$. The prevalence of senile cataract was observed to be significantly associated with the age. In our study(30.72\%) cataract cases were male and(32.91\%) cataract cases were female, thus a MALE: FEMALE RATIO of $1: 1.51$.No statistically significant association was observed between the sex of the study participants.

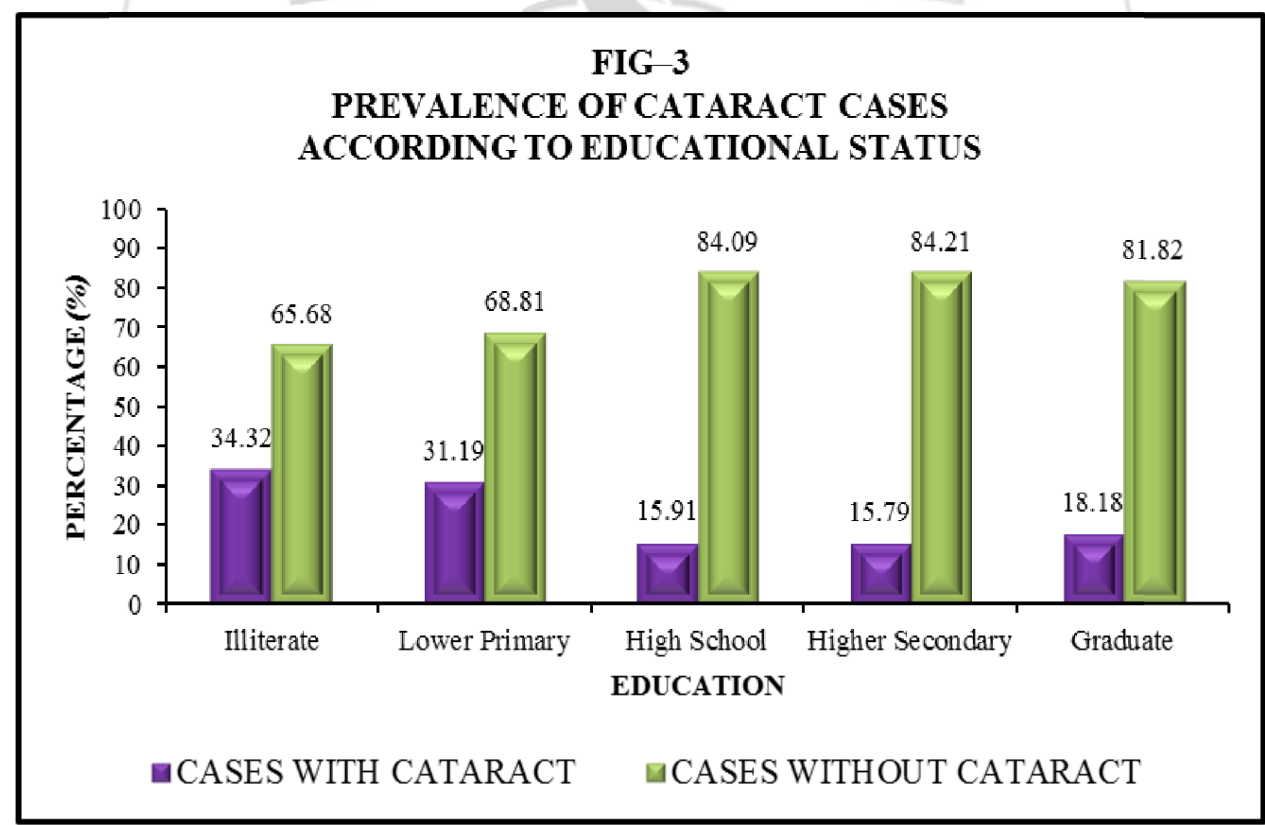

In our study illiterates were found to be having high observed between educational status of the study prevalence of 302 (34.32\%) than that of graduate 2 participants. (18.18\%).However, statistically significant association was 


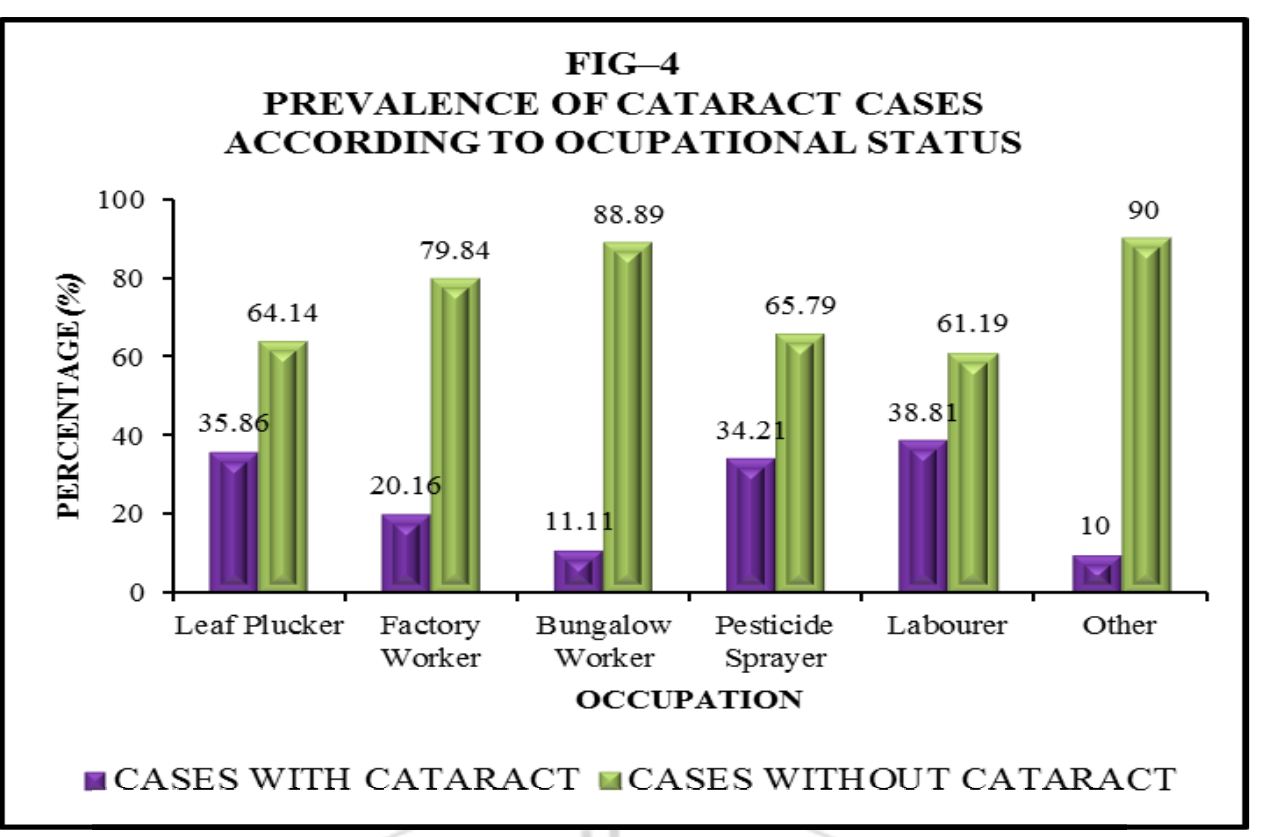

Maximum number of patients were outdoor workers. Prevalence is found to be maximum in labourer $38.81 \%$,followed by leaf plucker $35.86 \%$,pesticide sprayer $34.21 \%$,factory worker $20.16 \%$,bungalow worker $11.11 \%$ and least incidence in others $10 \%$.The association between occupations of the study participants is statistically significant.

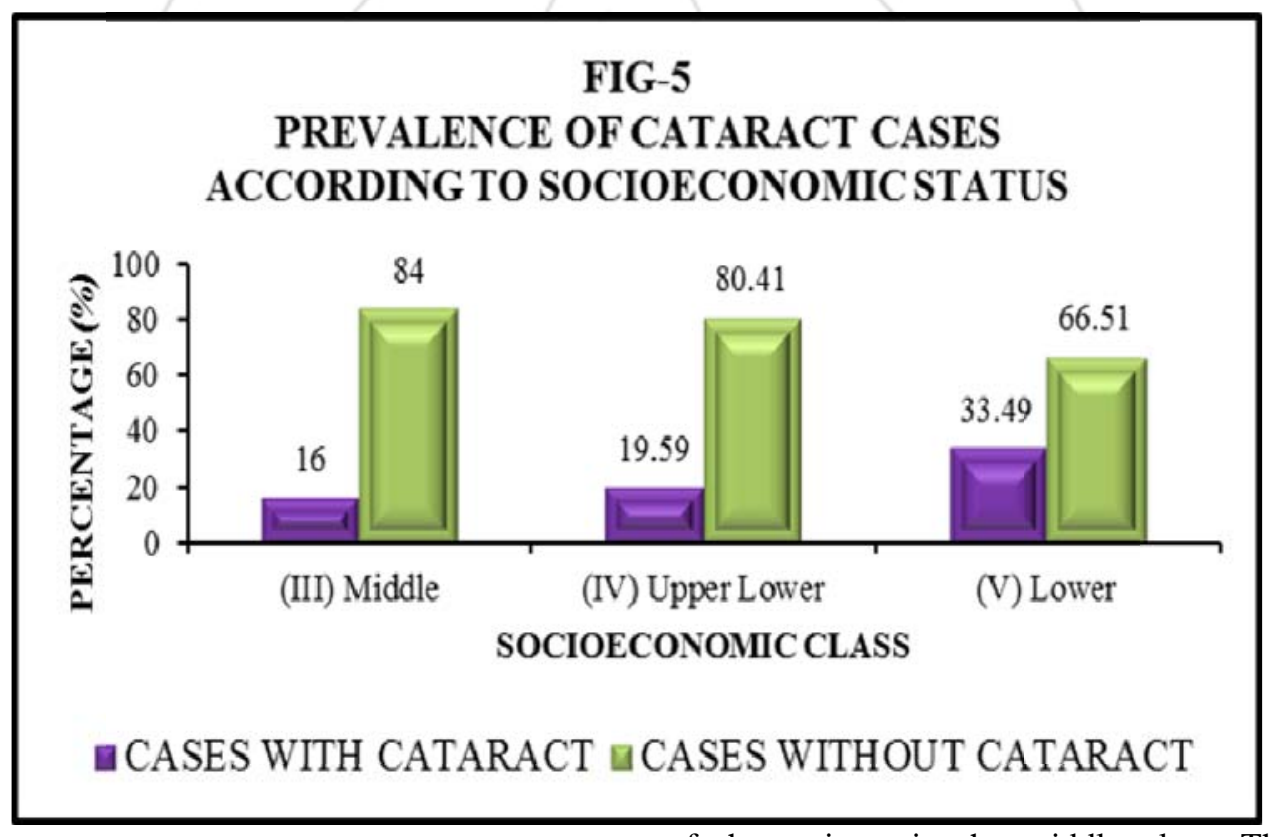

Most of the cases of cataract were of lower socioeconomic of the patients in the middle class. The prevalence of cataract was observed to be significantly associated with status, with $361(33.49 \%)$ of the patients in the lower class, socioeconomic status of the participants. 
International Journal of Science and Research (IJSR)

ISSN (Online): 2319-7064

Index Copernicus Value (2013): 6.14 | Impact Factor (2014): 5.611

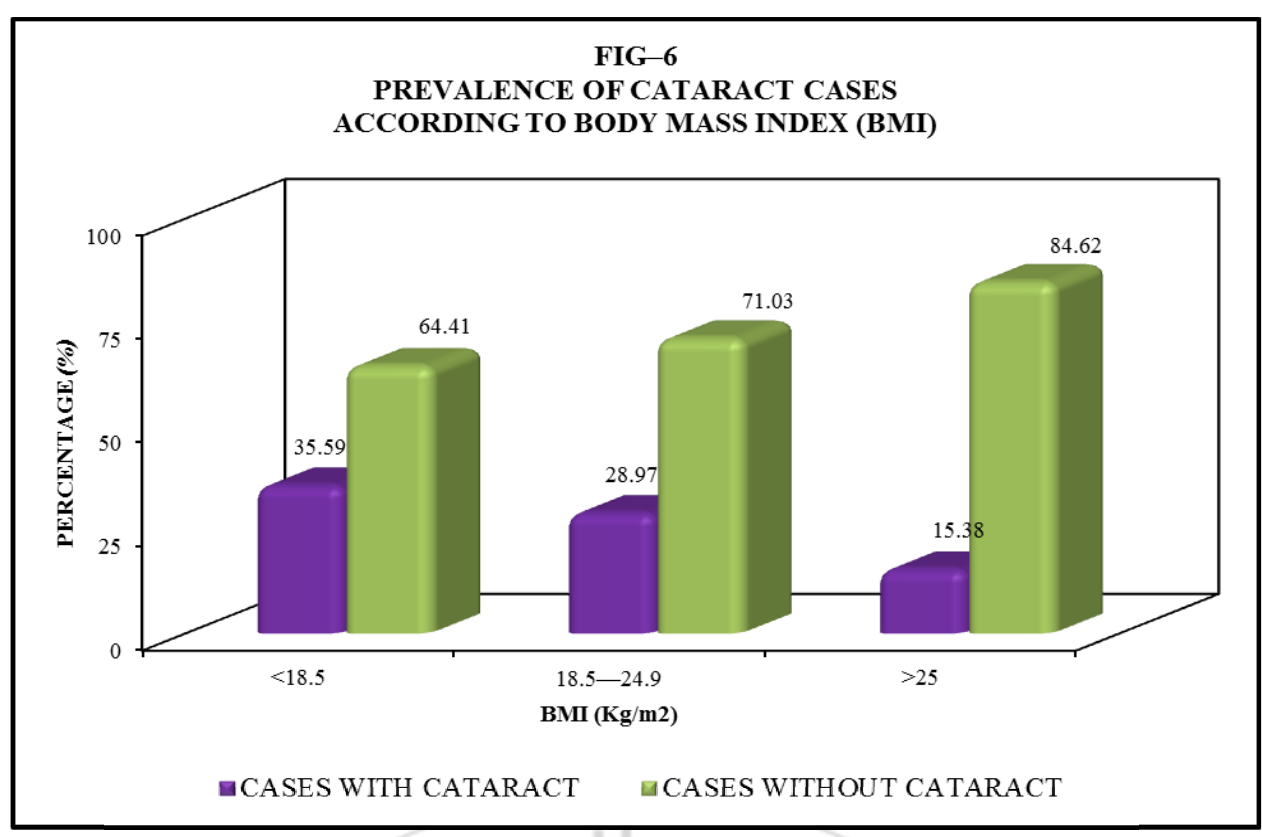

In our study, prevalence of cataract found to behigher in underweight patients i.e. $\mathrm{BMI}<18.5$ 205(35.59\%) than normal BMI i.e. 18.5-24.9 177(28.97\%) and overweight

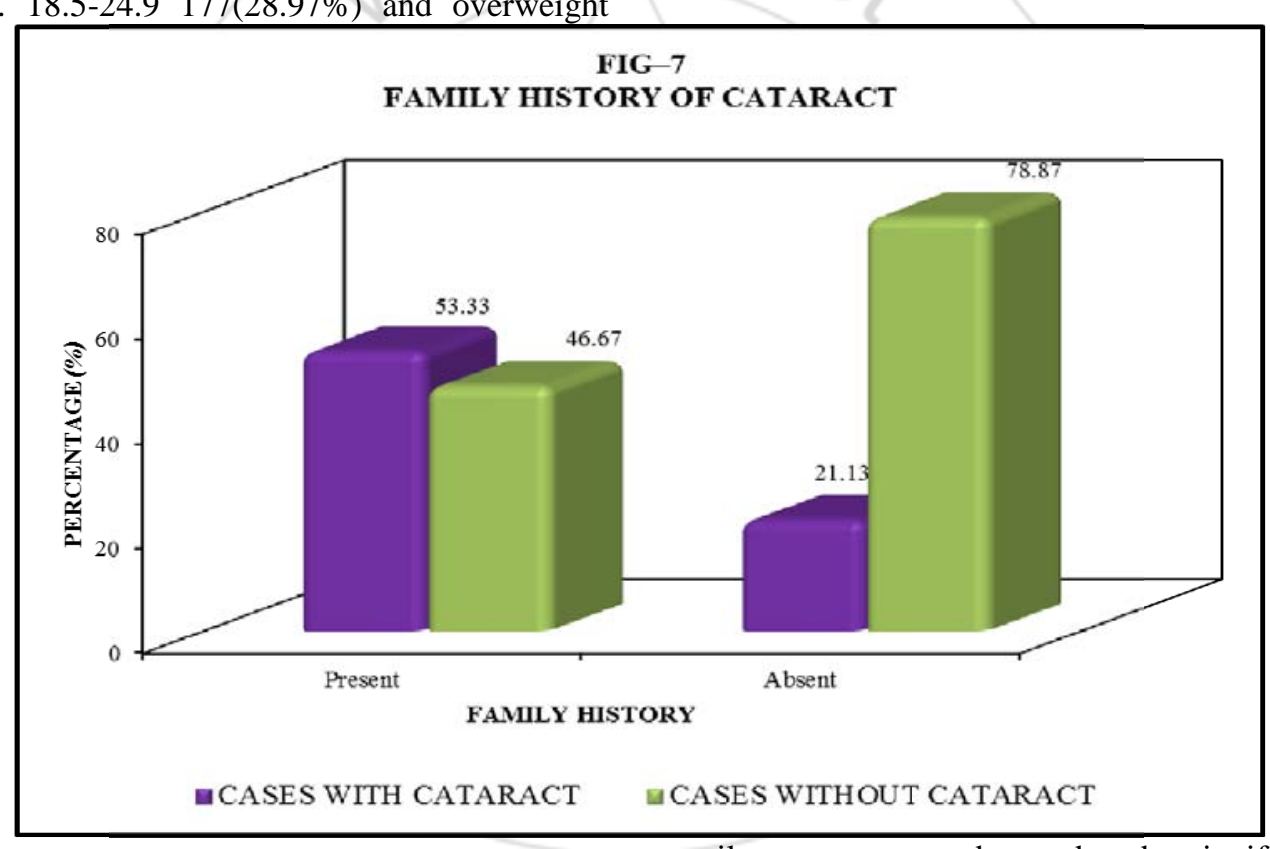

senile cataract was observed to be significantly associated with family history of cataract.

In our study, family history of cataract present in $53.33 \%$ and $21.13 \%$ did not have a family history. The prevalence of 


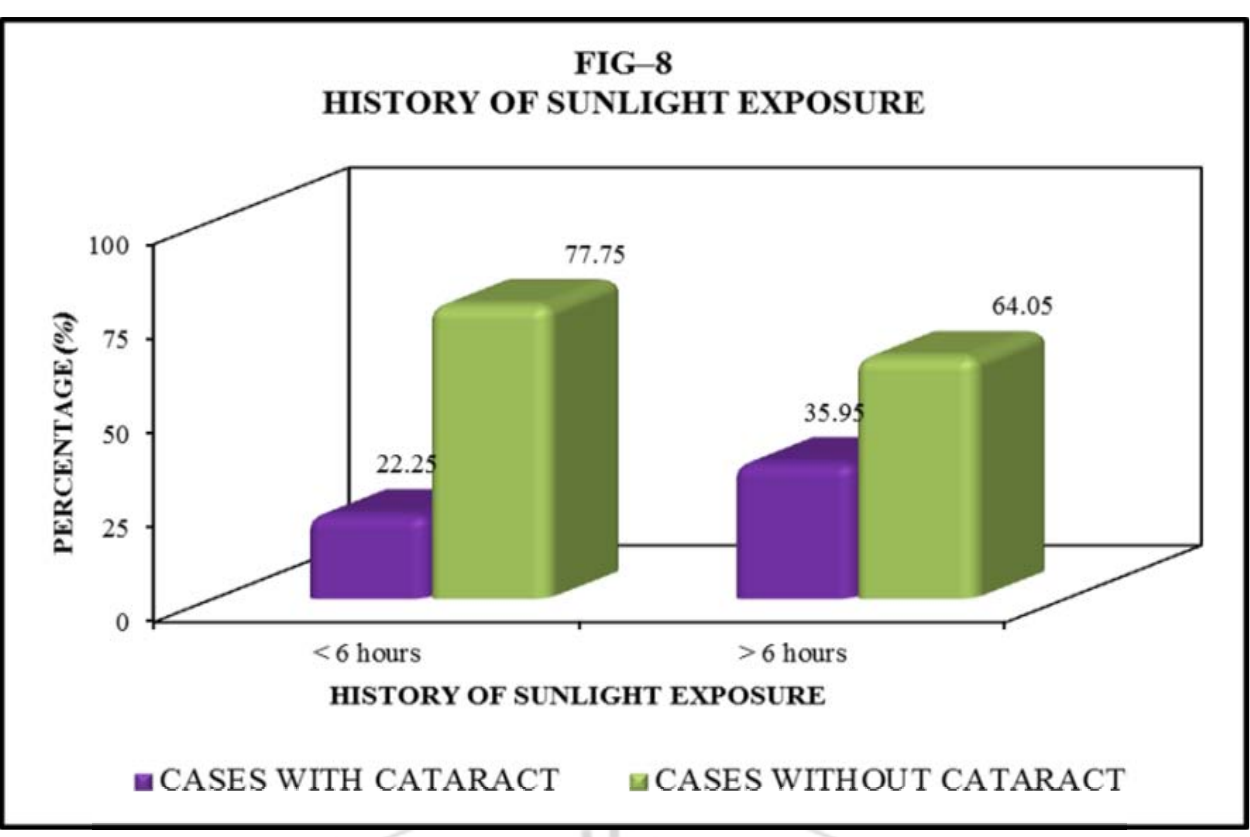

Prevalence is found to be more in those worked outdoor and exposed to sunlight $>6$ hours 307 (35.95\%) than those worked indoor or exposed $<6$ hours $77(22.25 \%)$. The association between duration of sunlight exposure of the study participants and prevalence of senile cataract was observed to be statistically significant.

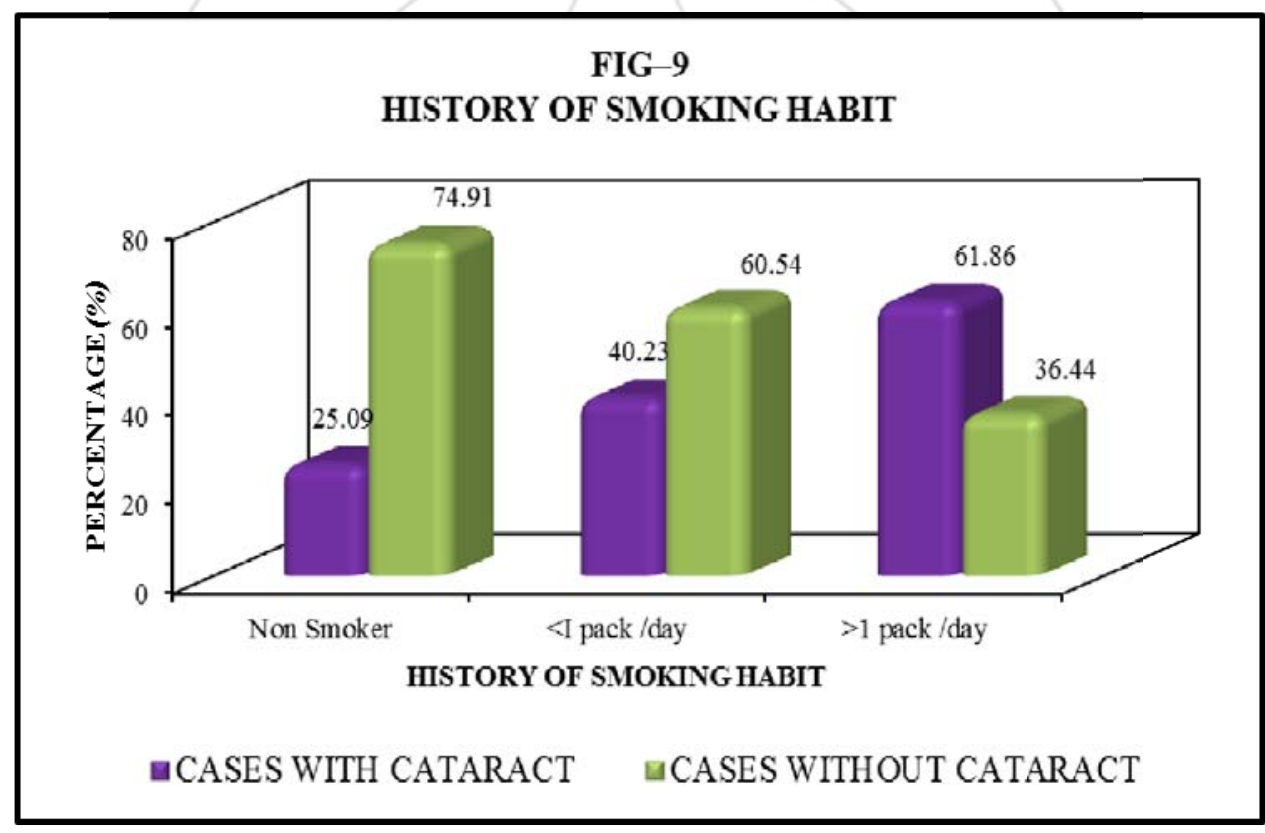

Prevalence is found to be more in those who smoked $>1$ pack senile cataract i.e.206(.25.09\%).The association between smoking habit of the study participants and prevalence of of bidi or cigarette 73(61.86\%)than those smoked less than 1 senile cataract was observed to be statistically significant. pack 105(40.23\%).Nonsmoker had lowest prevalence of 
International Journal of Science and Research (IJSR)

ISSN (Online): 2319-7064

Index Copernicus Value (2013): 6.14 | Impact Factor (2014): 5.611

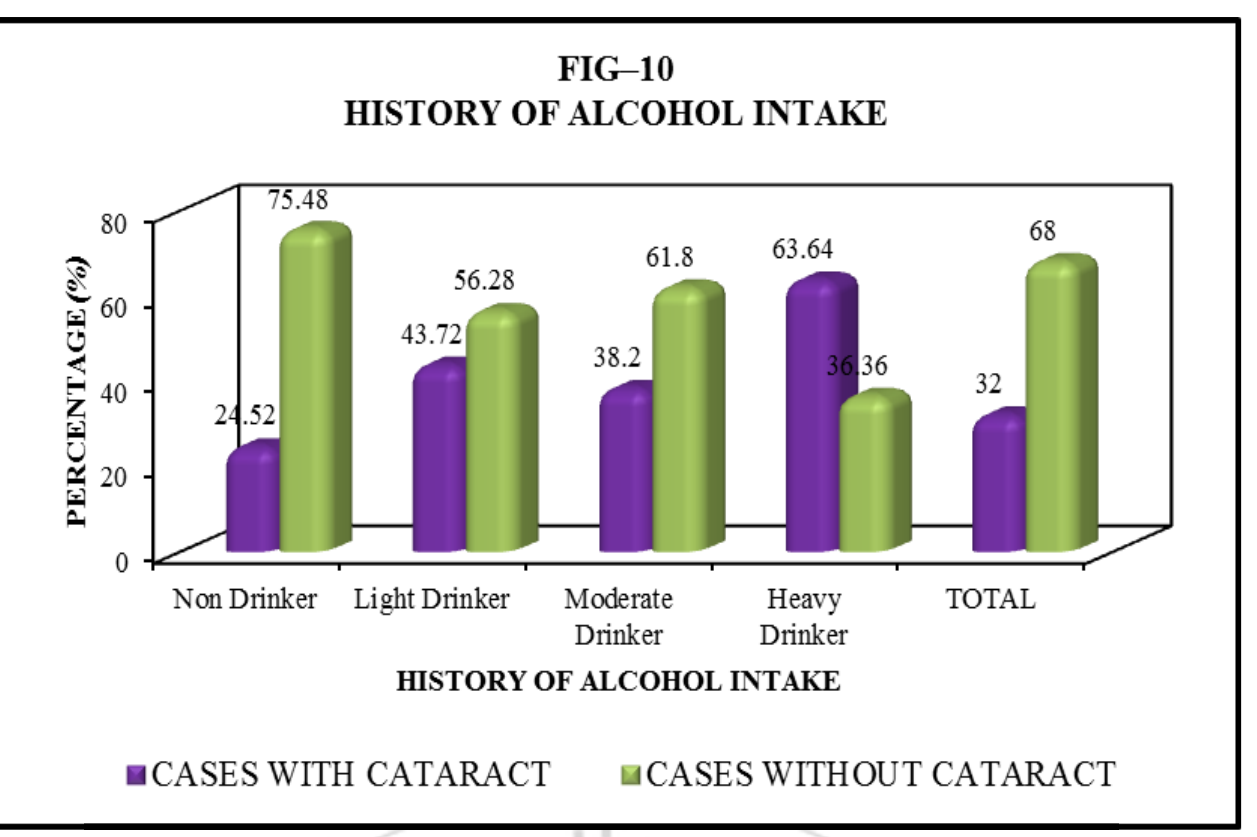

(One unit of alcohol is half pint $284 \mathrm{ml}$ of beer, or one glass wine or a single whiskey)

In this study cases those who were heavy drinkers with more than 4 (Unit/day) had prevalence 63.64\%,followed by light drinker (0-2 unit/day) had prevalence of $43.72 \%$ and moderate drinkers (2-4 unit/day) had prevalence of $38.20 \%$.Nondrinkers had a lowest prevalence of $24.52 \%$ in this study. The association between alcohol intake and senile cataract was observed to be statistically significant.

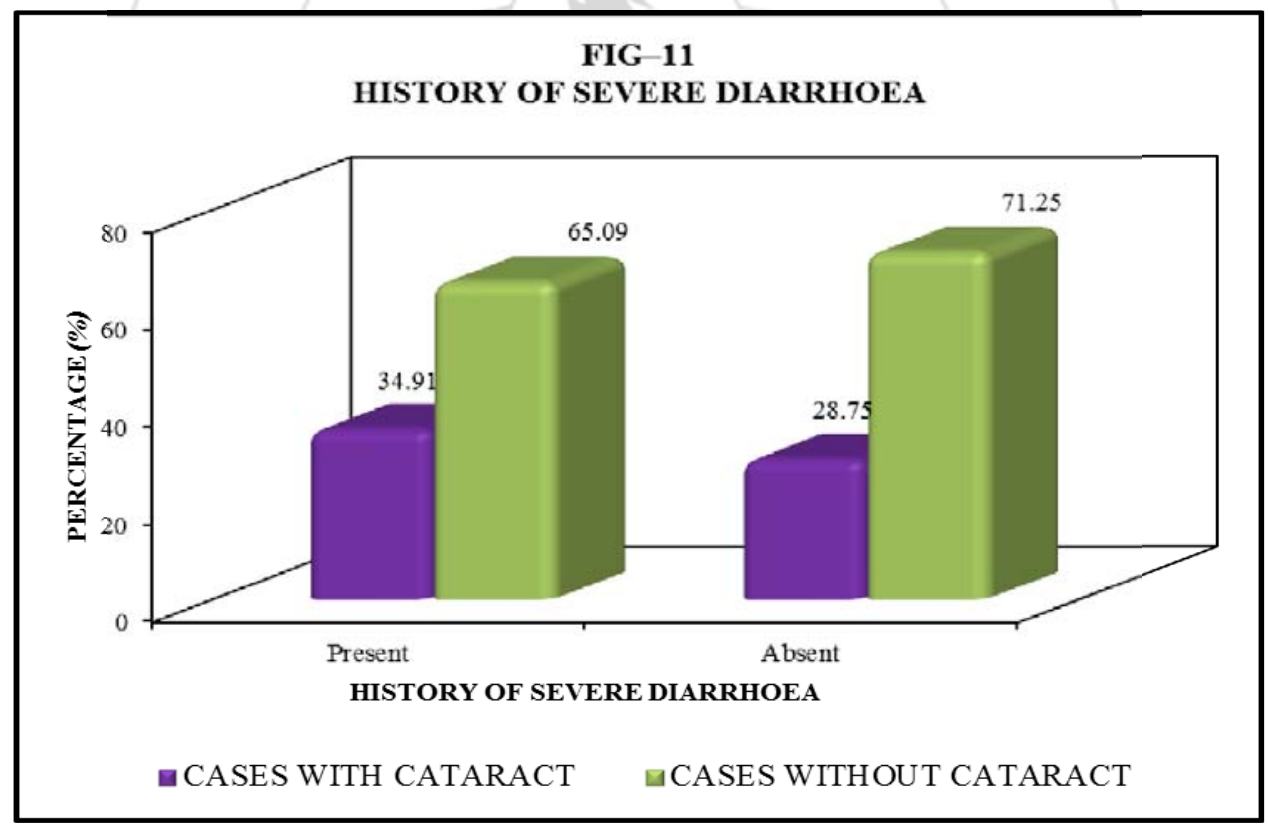

Prevalence of cataract was found to be more in those having a positive history of severe diarrhoea 221(34.91\%) than those who had not i.e (163) $28.75 \%$.The prevalence of senile cataract was observed to be significantly associated with history of severe diarrhoea.

In our study, the maximum number of cataract patients had less history of multivitamins intake 293(32.77\%) and cases without cataract have more history of taking multivitamins 91(29.74\%) However, the association between prevalence of senile cataract and multivitamin intake was not found to be statistically significant.

\section{UNIVARIATE \\ ANALYSIS \\ OF \\ FACTORSASSOCIATED WITH SENILE CATARACT}

\begin{tabular}{|c|c|c|c|}
\hline \multirow[b]{2}{*}{ Variables } & \multicolumn{2}{|c|}{ Cases } & \multirow[b]{2}{*}{$\begin{array}{c}\text { ODD'S RATIO } \\
\text { (95\% C.I.) }\end{array}$} \\
\hline & \begin{tabular}{|c|} 
With \\
Cataract
\end{tabular} & $\begin{array}{l}\text { Without } \\
\text { Cataract }\end{array}$ & \\
\hline \multicolumn{4}{|c|}{ Age Group (in years) } \\
\hline $40-49$ & 54 & 466 & Reference \\
\hline $50-59$ & 162 & 333 & $4.20(2.99-5.89)$ \\
\hline$>/=60$ & 168 & 17 & $\begin{array}{c}\text { 85.28(48.09- } \\
151.24)\end{array}$ \\
\hline \multicolumn{4}{|l|}{ Sex } \\
\hline Male & 153 & 345 & Reference \\
\hline
\end{tabular}

\section{Volume 5 Issue 3, March 2016}




\section{International Journal of Science and Research (IJSR) \\ ISSN (Online): 2319-7064}

Index Copernicus Value (2013): 6.14 | Impact Factor (2014): 5.611

\begin{tabular}{|c|c|c|c|}
\hline Female & 231 & 471 & $1.10(0.86-1.416)$ \\
\hline \multicolumn{4}{|l|}{ Educational Status } \\
\hline Illiterate & 302 & 578 & Reference \\
\hline Lower Primary & 63 & 139 & $0.87(0.62-1.20)$ \\
\hline High School & 14 & 74 & $0.36(0.20-0.65)$ \\
\hline Higher Secondary & 3 & 16 & $0.36(0.10-1.24)$ \\
\hline Graduate & 2 & 9 & $0.42(0.09-1.98)$ \\
\hline \multicolumn{4}{|l|}{ Occupation } \\
\hline \begin{tabular}{|l} 
Other \\
\end{tabular} & 7 & 63 & Reference \\
\hline Leaf Plucker & 222 & 397 & $5.03(2.26-11.78)$ \\
\hline Factory Worker & 25 & 99 & $2.27(0.93-5.56)$ \\
\hline Bungalow Worker & 6 & 48 & $1.12(0.35-3.56)$ \\
\hline Pesticide Sprayer & 39 & 75 & 4.68 (1.96-11.19) \\
\hline Labourer & 85 & 134 & $5.71(2.50-13.05)$ \\
\hline \multicolumn{4}{|c|}{ Socioeconomic Status } \\
\hline Lower & 361 & 717 & Reference \\
\hline Upper Lower & 19 & 78 & $0.48(0.28-0.81)$ \\
\hline \begin{tabular}{|l} 
Middle \\
\end{tabular} & 4 & 21 & $0.38(0.13-1.11)$ \\
\hline \multicolumn{4}{|l|}{$\operatorname{BMI}\left(\mathrm{Kg} / \mathrm{m}^{2}\right)$} \\
\hline$<18.5$ & 205 & 371 & Reference \\
\hline $18.5-24.9$ & 177 & 434 & $0.74(.0 .58-0.94)$ \\
\hline \multirow[t]{2}{*}{$>25$} & 2 & 11 & $0.32(0.072-1.50)$ \\
\hline & \multicolumn{2}{|c|}{ CASES } & \multirow[t]{2}{*}{ ODD’S RATIO } \\
\hline Variables & $\begin{array}{c}\text { With } \\
\text { Cataract } \\
\end{array}$ & \begin{tabular}{|l|} 
Without \\
Cataract
\end{tabular} & \\
\hline \multicolumn{4}{|l|}{$\begin{array}{l}\text { Family History of } \\
\text { Cataract }\end{array}$} \\
\hline Absent & 168 & 627 & Reference \\
\hline
\end{tabular}

\begin{tabular}{|l|c|c|c|} 
Present & 216 & 189 & $4.26(3.29-5.53)$ \\
\hline $\begin{array}{l}\text { History of Sunlight } \\
\text { Exposure (in hours) }\end{array}$ & & & \\
\hline$<6$ hours & 77 & 269 & Reference \\
\hline$>6$ hours & 307 & 547 & $1.96(1.47-2.61)$ \\
\hline History of Smoking Habit & & & \\
\hline Non Smoker & 206 & 615 & Reference \\
\hline <I pack /day & 105 & 158 & $2.02(1.54-2.71)$ \\
\hline 1 pack /day & 73 & 43 & 5.06 (3.38-7.58) \\
\hline History of Alcohol Intake & & & \\
\hline Non Drinker & 193 & 594 & Reference \\
\hline Light Drinker & 108 & 139 & $2.26(1.68-3.04)$ \\
\hline Moderate Drinker & 34 & 55 & $1.88(1.20-2.97)$ \\
\hline Heavy Drinker & 49 & 28 & $2.00(1.24-3.23)$ \\
\hline History of Severe Diarrhea & & & \\
\hline Absent & 163 & 404 & Reference \\
\hline Present & 221 & 412 & $1.33(1.04-1.70)$ \\
\hline History of Multivitamins & & & \\
\hline use & & & \\
\hline Absent & 91 & 215 & Reference \\
\hline Present & 293 & 601 & $1.17(0.88-1.54)$ \\
\hline
\end{tabular}

On univariate analysis, age, occupation, family history, sunlight exposure, smoking, alcohol consumption andhistory of severe diarrhea were found to be significantly associated with senile cataract.

Multiple Logistic Regression Of The Factors Associated With Senile Cataract VARIABLE IN THE EQUATION

\begin{tabular}{|c|c|c|c|c|c|c|c|c|}
\hline \multicolumn{9}{|c|}{ VARIABLE IN THE EQUATION } \\
\hline & \multirow[b]{2}{*}{$\mathrm{B}$} & \multirow[b]{2}{*}{ S.E. } & \multirow[b]{2}{*}{ Wald } & \multirow[b]{2}{*}{ df } & \multirow[b]{2}{*}{ Sig. } & \multirow[b]{2}{*}{$\operatorname{Exp}(B)$} & \multicolumn{2}{|c|}{ 95.0\% C.I. for EXP (B) } \\
\hline & & & & & & & Lower & Upper \\
\hline Age & & & 190.315 & 2 & 0 & & & \\
\hline 40-49 years & -4.48 & 0.326 & 189.284 & 1 & 0 & 0.011 & 0.006 & 0.021 \\
\hline 50-59 years & -3.116 & 0.299 & 108.88 & 1 & 0 & 0.044 & 0.025 & 0.08 \\
\hline Educational status & & & 11.249 & 4 & 0.024 & & & \\
\hline Graduate & 3.158 & 1.873 & 2.842 & 1 & 0.092 & 23.523 & 0.598 & 924.605 \\
\hline Higher secondary & 2.668 & 1.331 & 4.02 & 1 & 0.045 & 14.405 & 1.062 & 195.451 \\
\hline High school & 1.096 & 0.738 & 2.209 & 1 & 0.137 & 2.992 & 0.705 & 12.7 \\
\hline Lower primary & 0.836 & 0.281 & 8.836 & 1 & 0.003 & 2.308 & 1.33 & 4.006 \\
\hline Occupation & & & 24.704 & 5 & 0 & & & \\
\hline Other & -0.523 & 1.003 & 0.272 & 1 & 0.602 & 0.592 & 0.083 & 4.231 \\
\hline Bungalow & 0.248 & 1.2 & 0.043 & 1 & 0.836 & 1.282 & 0.122 & 13.479 \\
\hline Factory & 0.278 & 1.104 & 0.063 & 1 & 0.801 & 1.321 & 0.152 & 11.499 \\
\hline Leaf plucker & 0.918 & 0.273 & 11.275 & 1 & 0.001 & 2.503 & 1.465 & 4.277 \\
\hline Socioeconomic status & & & 1.117 & 2 & 0.572 & & & \\
\hline CLASS III & -1.218 & 1.61 & 0.572 & 1 & 0.449 & 0.296 & 0.013 & 6.94 \\
\hline CLASS IV & 0.233 & 0.676 & 0.118 & 1 & 0.731 & 1.262 & 0.335 & 4.747 \\
\hline BMI & & & 0.37 & 2 & 0.831 & & & \\
\hline$\geq 25$ & 0.183 & 0.926 & 0.039 & 1 & 0.843 & 1.201 & 0.195 & 7.38 \\
\hline $18.5-24.9$ & -0.097 & 0.175 & 0.306 & 1 & 0.58 & 0.908 & 0.645 & 1.278 \\
\hline Positive Family history of cataract & -1.615 & 0.176 & 83.861 & 1 & 0 & 0.199 & 0.141 & 0.281 \\
\hline Sunlight exposure $>6$ hours & -1.067 & 1.057 & 1.018 & 1 & 0.313 & 0.344 & 0.043 & 2.733 \\
\hline Alcohol & & & 31.852 & 3 & 0 & & & \\
\hline Non drinker & -1.65 & 0.384 & 18.46 & 1 & 0 & 0.192 & 0.091 & 0.408 \\
\hline Mild drinker & -0.741 & 0.406 & 3.341 & 1 & 0.068 & 0.476 & 0.215 & 1.055 \\
\hline Moderate & -1.013 & 0.47 & 4.654 & 1 & 0.031 & 0.363 & 0.145 & 0.911 \\
\hline Smoking habit & & & 22.821 & 2 & 0 & & & \\
\hline Constant & 4.982 & 0.509 & 95.934 & 1 & 0 & 145.768 & & \\
\hline
\end{tabular}

\section{Volume 5 Issue 3, March 2016}




\section{International Journal of Science and Research (IJSR) \\ ISSN (Online): 2319-7064 \\ Index Copernicus Value (2013): 6.14 | Impact Factor (2014): 5.611}

On multivariate analysis, age, educational status, occupation, family history, smoking and alcohol consumption were found to be significantly associated with senile cataract.

\section{Discussion}

In the present study we have taken the study population from tea garden community people of Dibrugarh who belonged to the age group of $\geq 40$ years. It was foundthat the prevalence of senile cataract among tea garden people to be $\mathbf{3 2} \%$.

In our study, out of 1200 total cases, prevalence of senile cataract increases with increasing age, maximum at age $\geq 60$ years (90.81\%) lowest at 40-49yr range (10.38\%).The prevalence of senile cataract was observed to be significantly associated with the age of the participants.Aravind Comprehensive Eye Study (2004) conducted a study in rural population of Southern Indiathey found that theprevalence of definite age related cataracts of all types increased significantly (p,0.001) with increasing age, from $15.7 \%$ among those aged $40-49$ years to $79.4 \%$ among those aged $>70$ years They found significant association ofage withsenile cataract. ${ }^{6}$ Husain $\mathrm{R}$ et $a l$,(2005)in their study in rural population of Indonesia found that $82.8 \%$ of $>60$ yrs. of age study participants have cataract. They found significant association ofage withsenile cataract. ${ }^{7}$ Rim et al (2014) in their study conducted in South Korean population found that $97.9 \%$ ofstudy population of $\geq 80$ had cataract. They alsofound a significant association of age with cataract. ${ }^{8}$

In our study, maximum number of patients was outdoor workers. Prevalence is found to be maximum in labourer(38.81\%),followed byleaf Plücker(35.86\%), pesticide sprayer(34.21\%), factory worker(20.16\%), bungalow worker $11.11 \%$ and least incidence in others $10 \%$.The association between occupation of the study participants and prevalence of senile cataract was observed to be statistically significant.Bandhu.S.D et al.(2015) conducted a study of morphology of cataract in western India and they found in their study that that the type of occupation was significantly associated with type of cataract ${ }^{9}$ Kanagaranjan.P.et.al,(2011)found that agricultural workers show significant association $(\mathrm{p}<0.05)$ with cataract blindness. ${ }^{10}$

In ourstudy, most of the cases of cataract were of lower socioeconomic status, with $361(33.49 \%)$ of the patients in the lower class, 19 (19.59\%) of the patients in the upper lower and $7(16 \%)$ of the patients in the middle class. The prevalence of cataract was observed to be significantly associated with socioeconomic status of the participants. Study conducted by Ughade SN et al (1998) observed significantly higher prevalence of any cataract in the extremely low socioeconomic group. ${ }^{11}$ Krishnaiah $\mathrm{S}$ et al(2005). Conducted a study among peoples of Andhra Pradesh observed significantly higher prevalence of any cataract in the extremely low socioeconomic group. ${ }^{12}$ Similarly, Kuper $\mathrm{H}$ et al.(2008)observed that people with visual impairment due to cataract were poorer than those with normal sight in all three low-income countries (Kenya, Bangladesh, and the Philippines) in their study. ${ }^{13}$

In our study is found that most of the cataract cases were underweight BMI i.e. <18.5 205(35.59\%). 29.2\% prevalence among normal BMI i.e.18.5-24.9 and prevalence of $15.38 \%$ among overweight BMI>25.A statistically significant association was observed between BMI and prevalence of cataract. Study conducted byCaulfield.L.E.et al. (1999) observed a significant association $(\mathrm{P}<0.05)$ between low $\mathrm{BMI}$ and cataract specifically nuclear opacity ${ }^{14}$.Foster.P.J.et al(2003) observed a significant association between People with the lower quintiles of BMI and Nuclear cataract (test of trend, $\mathrm{p}=0.03)^{15}$.

In our study,216 cases had a positive family history of cataract $53.33 \%$ and 168 did not have a family $21.13 \%$ Family history was found to be significantly associated with cataract. Sreenivas S et al.(1999) found that family history of cataract was significantly associated with cataract in Angamally centre. ${ }^{16}$

Our study foundthatprevalence of cataract to be more in those worked outdoor and exposed to sunlight $>6$ hrs. 307 (35.95\%) than those worked indoor or exposed $<6$ hrs. $77(22.25 \%)$. The association between duration of sunlight exposure of the study participants and prevalence of senile cataract was observed to be statistically significant. Hiller.S. et al. using HANES data found the exposure of sunlight per day is significantly associated with senile cataract. ${ }^{17}$ Sreenivas.S et al(1999) found a linear doseresponse relation was also observed with the increased duration of exposure per day. Statistically significant relation of cataractwas found to be more in those who exposure to sunlight $>4$ hours of per day. ${ }^{16}$

In our study prevalence is found to be more in those who smoked $>1$ pack of bidi or cigarette $73(61.86 \%)$ than those worked smoke less than 1 pack 105(40.23\%).Nonsmoker had lowest prevalence of senile cataract i.e.206(.25.09\%) The association between smoking habit of the study participants and prevalence of senile cataract was observed to be statistically significant. Harding JJ.et al 1988 conducted a clinic based case-control study of 300 cases and 609 controls in Oxfordshire, England, found thatheavy smoking was associated withincreased risk of cataract. ${ }^{18}$ Aravind Comprehensive Eye Study (2004) conducted a study in rural population of southern Indiafoundthat moderate to heavy smoking statistically significant associated with nuclear and cortical cataracts in their study ${ }^{6}$ Bandhu.S.D.et.al (2015) found in their study that Eighty-eight (44.4\%) subjects of the study population consumed tobacco. The association between cataract morphology and tobacco consumption was found to be significant. $^{10}$

In our studyprevalence was found to be high in heavy drinkers(>4Units/day) i.e.63.64\%,followed by light drinker (0-2 unit/day) had prevalence of $43.72 \%$ and moderate drinkers (2-4 units/day) had prevalence of $38.20 \%$.Nondrinkers had a lowest prevalence of $24.52 \%$ in this study.The association between alcohol intake and senile cataract was observed to be statistically significant.Harding JJ.et al (1988) conducted a clinic based case-control study of 300 cases and 609 controls in Oxford shire;England heavy beer drinking was associated with a two-fold increased risk of cataract. $^{18}$ 


\section{International Journal of Science and Research (IJSR) \\ ISSN (Online): 2319-7064 \\ Index Copernicus Value (2013): 6.14 | Impact Factor (2014): 5.611}

In our study prevalence of cataract was found to be more in those having a positive history of severe diarrhoea $221(34.91 \%)$ than those who had not i.e. (163) $28.75 \%$. The prevalence of senile cataract was observed to be significantly associated with history of severe diarrhea. Harding JJ.et al( 1988 ) conducted a clinic based casecontrol study of 300 cases and 609 controls in Oxfordshire, England, found Severe diarrhoea appeared as a marginal risk factor for cataract when comparing all cases and all controls ( $\mathrm{p}=0-05$ X2 test; relative risk 1.6) but was found to be a stronger risk factor in those aged 70 to 79 years. Nevertheless, severe diarrhoea is only a marginal risk factor in the Oxford population. ${ }^{17}$ Echebiri.S.I.et.al (2010) conducted Case-Control Studies in Lagos (Lagos group), South Western Nigeria, and Kano (Kano group), North Central Nigeria and Risk Factors for Cataract in Two Population Studies in Nigeria found that 22 (11.0\%) cases with severe diarrhea had cataract. They found a statistically significant association between severe diarrhea and senile cataract. $^{19}$

\section{UNIVARIATE ANALYSIS FOR FACTOR ASSOCIATED WITH CATARACT}

In the present study, on univariate analysis age, educational status, occupation, socioeconomic status, BMI, family history, history of sunlight exposure, smoking, alcohol consumption and severe diarrhea were found to be significantly associated with senile cataract.Ughade SN et al. (1998) in their study on univariate analysis found education, socioeconomic status, family history, alcohol intake, smoking, sunlight exposure and history of severe diarrhea were found to be significantly associated with senile cataract. ${ }^{11}$ Rim et.al (2014) in their study on univariate analysis found age, education, occupation, socioeconomic status, BMI, alcohol intake and sunlight exposure were found to be significantly associated with senile cataract. ${ }^{8}$

\section{MULTIVARIATE ANALYSIS OF FACTOR ASSOCIATED WITH CATARACT}

In the present study, on multivariate analysis age, educational status, occupation, family history, smoking and alcohol consumption were found to be significantly associated with senile cataract. Ughade SN et al. (1998)in their study on multivariate analysis found education, socio economic status, literary status and history of severe diarrhea were found to be significantly associated with senile cataract. ${ }^{11}$ Nirmalan PK, et al.( 2004) on multivariate analysis age,sex, literary status, BMI and smoking were significantly associated with senile cataract. ${ }^{6}$ Rim et.al(2014) in their study on multivariate analysis found age, education, socio economic status, BMI,alcohol intake and sunlight exposure were found to be significantly associated with senile cataract. ${ }^{8}$

\section{Conclusions and Recommendations}

The present study concluded with the findings highlighting the huge burden of cataract in tea garden community of India and the role of increasing age, low literacy status, outdoor occupation,family history of cataract, low BMI, smoking habit, alcohol addiction and severe diarrhea incataractogenesis pointing towards amulti-factorial causation. Therefore, to tackle thisproblem of cataract, a multi-pronged strategy isrequired. Some of these identified risk factors likelow literacy, outdoor occupation, low BMI smoking habit, alcohol addiction and severe diarrhea havethe potential for being modified through various public health interventions including awarenessgeneration regarding these factors and possible modes of prevention like use of protective equipmentfor eyes by those involved in outdoor occupations and improving nutritional status by not only emphasizing on the quantity but also the quality of diet health educationandlife style modification. Also, implementation of measures for improvingliteracy status is required which, directly or indirectly, has an impact, not only on cataract but also on overall health of an individual and that of thenation as a whole.

\section{References}

[1] Pascolini D, Mariotti SP: Global estimates of visual impairment: 2010. Br J Ophthalmol 2012, 96(5):614 618

[2] The global burden of disease : 2004 update. Geneva, Switzerland: Wold Health Organization. $r$ p. 35.ISBN9789241563710

[3] Kansupada KB, Sassani JW. Sushruta: The father of Indian surgery and ophthalmology. DocumentaOphthalmologica93;(1-2):159-167.

[4] Baroowah, G. P., 2006 : The Legend, Life and Livelihood of India, Guwahati, india, LBS Publications, 75-77.

[5] Sobti S \&Sahni B Cataract among adults aged 40 years and above in a rural area of Jammu district in India: Prevalence and Risk-factors. International J. of Healthcare \& Biomedical Research, Volume: 1, Issue: 4, July 2013, Pages 284-296,284 www.ijhbr.com

[6] Nirmalan PK, Robin AL, Katz J, Tielsch JM, Thulasiraj RD, Krishnadas R et al. Risk factors for age related cataract in a rural population of southern India: the Aravind Comprehensive Eye Study. $\mathrm{Br} \mathrm{J}$ Ophthalmol 2004;88(8):989-94.

[7] Hussain R.et.al. Prevalence of Cataract in Rural Indonesia, Ophthalmology 2005;112:1255-1262 (C) 2005 by the American Academy of Ophthalmology

[8] Rim.T et al Cataract subtype risk factors identified from the Korea National Health and Nutrition Examination survey 2008-2010,BMC Ophthalmology 2014, 14:4 Page 2 of 15

[9] Seema DuttBandhuYogendraGanpatVabale, Prajakta Pradeep Sambarey, Swati Sanjeev Raje1 A study of morphology of cataract in western India Journal of Clinical Ophthalmology and Research - May-Aug 2015 - Volume 3 - Issue 2

[10] Kanagaranjan.P,Nandi.P,Lokeshmaran.-A.Prevalence of cataract blindness in a rural Puducherry,Indian medical gazette, page 348-352 September 2011

[11] Ughade SN, Zodpey SP, Khanolkar VA. Risk factors for cataract: A case control study. Indian J Ophthalmol 1998;46(4):221-7.

[12] Krishnaiah S, Vilas K, Shamanna BR, Rao GN, Thomas R, Balasubramanian D. Smoking and its association with Cataract: Results of the Andhra Pradesh Eye Disease Study from India. Investigative Ophthalmology and Visual Science 2005;46(1):58-65. 


\section{International Journal of Science and Research (IJSR) \\ ISSN (Online): 2319-7064}

Index Copernicus Value (2013): 6.14 | Impact Factor (2014): 5.611

[13] Leske MC, Chylack LTJ, Wu SY. The Lens Opacities Case-Control Study. Risk factors for cataract. Archives of Ophthalmology 1991; 109: 244-251.

[14] Caulfield LE, West SK, Barron Y, et al. Anthropometric status and cataract: the Salisbury Eye Evaluation project. Am J ClinNutr 1999;69:237-42

[15] Foster PJ, Wong TY, Machin D, Johnson GJ, Seah SKL. Risk factors for nuclear, cortical and posteriorsubcapsular cataracts in the Chinese population of Singapore: the TanjongPagar Survey. Br J Ophthalmol. 2003;87(9):1112-20.

[16] ShnubhatlaSreenivas 1, Amble K Prabhakar 1et al.A.Rural Population Based Case Control Study Of Senile Cataract in India, J Epidemiology vol 9 no5 nov 1999; 9 : 327-336.

[17] Hiller R, Giacommeti L, Yuen K: Sunlight and cataract: An epidemiologic investigation. Am J Epidemiol 1977; 105:450459.

[18] Harding JJ, van Heyningen R. Acase control study of cataract in oxfordshire :some risk factors,British journal of ophthalmology 1988, 72, 804-808

[19] Echebiri,S.I, Odeigah, P. G. C.and Myers S. N.1 CaseControl Studies and Risk Factors for Cataract in Two Population Studies in Middle East Afr J Ophthalmol. 2010 Oct-Dec; 17(4): 303-309. 